\title{
Avaliação da resistência ao cisalhamento do compósito Right-On em diferentes condições de esmalte
}

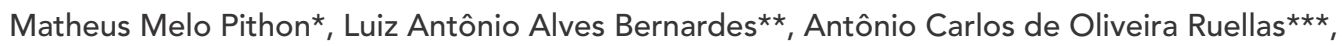

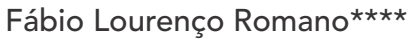

\begin{abstract}
Resumo
Objetivo: avaliar a resistência ao cisalhamento da união de braquetes metálicos colados com o compósito Right-On, em diferentes condições de superfície. Material e métodos: foram utilizados 45 incisivos inferiores permanentes bovinos divididos em três grupos $(n=15)$. No grupo 1 (controle), as colagens foram realizadas com Transbond XT seguindo as recomendações do fabricante, ou seja condicionamento com ácido fosfórico a 37\%, lavagem, secagem, aplicação de XT primer e colagem propriamente dita. Nos outros dois grupos, os braquetes foram colados com Right-On, sendo que no grupo 2 seguiu-se as instruções do fabricante, ou seja condicionamento com ácido fosfórico a 37\%, aplicação do líquido ativador do compósito na superfície condicionada e na base do braquete e posterior inserção do compósito na base do braquete e posicionamento. No grupo 3 a superfície dentária foi condicionada com o ácido-primer Transbond Plus Self-Etching Primer e líquido ativador do compósito foi aplicado apenas na base do braquete. Após a colagem, realizou-se o ensaio de cisalhamento de toda amostra à velocidade de 0,5mm por minuto em máquina Instron de ensaios mecânicos. Resultados e conclusões: os resultados (MPa) mostraram não haver diferenças estatísticas entre os grupos 1 e 2 (p > 0,05), entretanto estes grupos foram estatisticamente superiores ao grupo $3(\mathrm{p}<0,05)$. Os resultados do IRA evidenciaram maior número de fraturas na interface braquete/compósito.
\end{abstract}

Palavras-chave: Resistência ao cisalhamento. Colagem dentária. Braquetes.

\section{INTRODUÇÃO}

Até a década de 70, a fixação dos acessórios ortodônticos ao dente era feita com bandas em todos os dentes. De acordo com Zachrison ${ }^{20}$, muitas eram as desvantagens desse procedimento, como dificuldade de higienização, complexidade, moro- sidade de sua execução clínica, comprometimento da estética, entre outras. Dessa forma, a técnica de colagem direta dos acessórios ortodônticos foi um avanço imprescindível para o desenvolvimento, simplificação e expansão da Ortodontia. A técnica de colagem direta só foi possível com o advento

\footnotetext{
* Especialista em Ortodontia pela Universidade Federal de Alfenas-UNIFAL. Mestre em Ortodontia pela Universidade Federal do Rio de Janeiro - UFRJ.

** Mestre em Ortodontia pela Universidade Federal do Rio de Janeiro - UFRJ. Professor do curso de especialização em Ortodontia da Universidade Federal de Alfenas - UNIFAL.

*** Mestre e Doutor em Ortodontia pela Universidade Federal do Rio de Janeiro- UFRJ. Professor adjunto de Ortodontia pela Universidade Federal do Rio de Janeiro - UFRJ. Professor do curso de especialização em Ortodontia da Universidade Federal de Alfenas - UNIFAL.

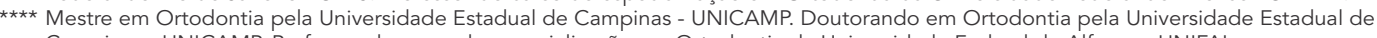
Campinas - UNICAMP. Professor do curso de especialização em Ortodontia da Universidade Federal de Alfenas - UNIFAL.
} 
do condicionamento ácido ao esmalte dentário, descrita por Buonocore ${ }^{6}$, em 1955, tornando a colagem de braquetes rotina no tratamento com aparatologia fixa.

$\mathrm{O}$ primeiro artigo de que se tem referência sobre a colagem de braquetes diretamente sobre a superfície dentária foi descrito por Sadler ${ }^{16}$. Segundo Nordenvall, Branstron e Malmgren ${ }^{13}$, esta técnica trouxe grandes vantagens para a Ortodontia, dentre elas: a não-interferência no contato proximal $^{5}$, a fácil colagem e remoção de acessórios, diminuição do tempo de cadeira, estética, higiene e menor irritação à gengiva ${ }^{5,11}$.

Atualmente, a grande diversidade de materiais indicados para colagem de braquetes ortodônticos ao esmalte dentário e o conhecimento científico dos materiais usados são de fundamental importância para o uso clínico. Dentre esses materiais destacam-se os compósitos, que possuem características como boa resistência, dureza e estabilidade dimensional ${ }^{9}$, embora deixem a desejar quanto à viscosidade, tempo de trabalho $\mathrm{o}^{1,2,6,7,10,12,15,17}$ e liberação de flúor ${ }^{14}$.

$\mathrm{Na}$ literatura existe uma infinidade de trabalhos comparando compósitos entre si e estes com outros materiais. A prática clínica mostra que é possível obter uma colagem satisfatória com vários materiais, cada qual com a sua técnica ${ }^{2,3,10,12,15,17}$. Com isso, o foco dos pesquisadores mudou, passando da situação de procura incessante por maior resistência a uma situação de manutenção da resistência conseguida, com simplificação do método e consecutiva diminuição no tempo de cadeira ${ }^{2,3,4,8}$.

O objetivo do presente estudo foi avaliar a resistência ao cisalhamento e o índice de remanescente de adesivo (IRA) do Right-On (TP Ortho, Tokyo, Japão) que é um compósito no mix (sem mistura) colado em diferentes condições de superfície de esmalte e com modificação da técnica de colagem.

\section{MATERIAL E MÉTODOS}

Neste estudo in vitro foram utilizados 45 inci- sivos inferiores permanentes bovinos, devidamente limpos, armazenados em solução de formol a $10 \%$ e estocados em geladeira à temperatura aproximada de $6^{\circ} \mathrm{C}$.

Os dentes foram incluídos em anéis de PVC rígido (Tigre, Joinville, Brasil) com gesso-pedra especial (Durone - Dentsply, Petrópolis, Brasil), de tal forma que apenas suas coroas ficaram expostas. $\mathrm{Na}$ inclusão, as superfícies vestibulares dessas coroas foram posicionadas perpendicularmente à base do troquel, com o auxílio de esquadro de vidro em ângulo de $90^{\circ}$, com finalidade de possibilitar correto ensaio mecânico (Fig. 1). Após a cristalização do gesso, todos os conjuntos foram armazenados em água destilada e novamente em geladeira.

Previamente à colagem, as superfícies vestibulares dos dentes receberam profilaxia com taça de borracha (Viking, KG Sorensen, Barueri, Brasil), pedra-pomes extra-fina (S.S. White, Juiz de Fora, Brasil) e água por 15 segundos, em seguida procedeu-se à lavagem com spray ar/água por 15 segundos e secagem com jato de ar livre de óleo e umidade pelo mesmo tempo. A cada cinco profila-

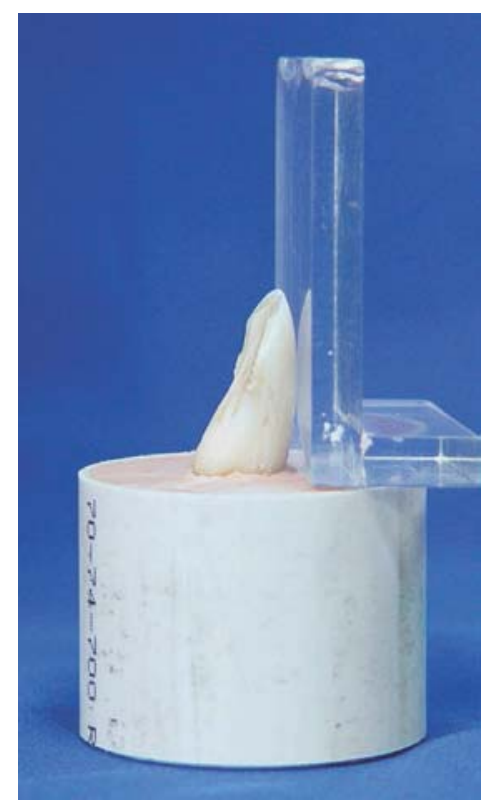

FIGURA 1 - Posicionamento das coroas dentárias em anel de PVC com auxílio de esquadro de vidro, deixando a superfície dentária perpendicular ao solo. 
xias a taça de borracha foi substituída para padronização do procedimento.

Após profilaxia, os corpos-de-prova foram divididos aleatoriamente em três grupos $(n=15)$, sendo que no grupo 1 (Controle), os braquetes de incisivos centrais superiores (Morelli, Sorocaba, São Paulo) foram colados com compósito Transbond XT (3M Unitek, Monrovia, USA); nos grupos 2 e 3 com o compósito Right-On (TP Ortho, Tokyo, Japão), como detalhado abaixo:

- Grupo 1: condicionamento do esmalte com ácido fosfórico a $37 \%$ por 15 segundos, lavagem e secagem pelo mesmo período de tempo, aplicação do XT primer, colagem dos braquetes com Transbond XT, remoção dos excesso, fotopolimerização por 40 segundos, sendo 10 segundos em cada face (mesial, distal, incisal e gengival) à distância de $1 \mathrm{~mm}$ do braquete com aparelho XL 1500 (3M, Dental Products, Monrovia, USA) com intensidade da lâmpada de $400 \mathrm{mw} / \mathrm{cm}^{2}$, aferida regularmente com radiômetro (Demetron, Danburry, CT, USA).

- Grupo 2: condicionamento do esmalte com ácido fosfórico a 37\% por 15 segundos, lavagem e secagem por mesmo período de tempo, aplicação do primer Right-On na base do braquete e na superfície condicionada, colocação do compósito Right-On na base do braquete, posicionamento e remoção dos excessos.

- Grupo 3: aplicação do Transbond Plus Self Etching Primer, esfregado por 3 segundos sobre o esmalte, leve jato de ar para espalhar o material, aplicação do primer Right-On na base do braquete, colocação do compósito Right-On na base do braquete, posicionamento e remoção dos excessos.

Foram utilizados braquetes de incisivos centrais superiores (Morelli, Sorocaba, Brasil) com área da base de $14,02 \mathrm{~mm}^{2}$.

Após a colagem, os corpos-de-prova foram armazenados em água destilada e mantidos em estufa durante 24 horas, à temperatura de $37^{\circ} \mathrm{C}$. O teste de resistência ao cisalhamento foi reali- zado em máquina universal de ensaios mecânicos (Instron, Corporation, Canton, USA), operando a uma velocidade de $0,5 \mathrm{~mm} / \mathrm{min}$, através de ponta ativa em cinzel (Fig. 2). Os resultados de resistência ao cisalhamento foram obtidos em Kgf, transformados em $\mathrm{N}$ e divididos pela área da base do braquete, fornecendo resultados em $\mathrm{MPa}$.

Após realização do teste de resistência ao cisalhamento, a superfície vestibular de cada corpo-de-prova foi avaliada em lupa estereoscópica (Carl Zeiss, Göttingen, Alemanha) com aumento de 8 vezes, para ser quantificado o Índice de Remanescente do Adesivo (IRA), conforme os critérios preconizados por Artun e Bergland ${ }^{1}$, ou seja: 0 para nenhuma quantidade de compósito aderido ao esmalte; 1 para menos da metade de compósito aderido ao esmalte; 2 para mais da metade de compósito aderido ao esmalte e 3 para todo o compósito aderido ao esmalte.

Os resultados do teste de resistência ao cisalhamento da união foram submetidos à análise de variância (ANOVA) e posteriormente ao teste de Tukey, para comparação do controle com os de-

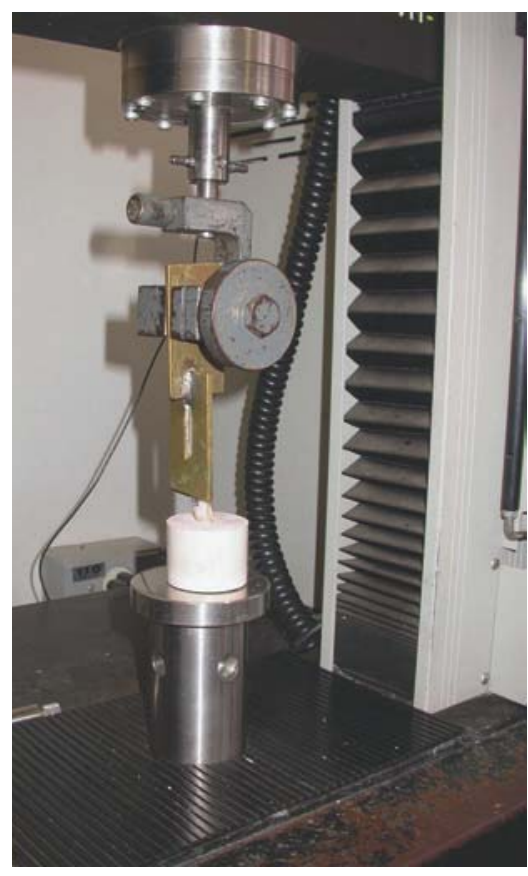

FIGURA 2 - Corpo-de-prova posicionado em máquina Instron para teste de cisalhamento com velocidade de $0,5 \mathrm{~mm} / \mathrm{min}$, utilizando-se ponta em cinzel. 
mais tratamentos. Na avaliação dos escores do IRA foi utilizado o teste de Kruskal-Wallis.

\section{RESULTADOS}

$\mathrm{Na}$ comparação dos valores de resistência ao cisalhamento (Tab. 1) não foram encontradas diferenças estatísticas significantes entre os grupos 1 (Transbond XT convencional) e 2 (Right-On) seguindo as recomendações do fabricante $(p>0,05)$. Entretanto, estes grupos foram estatisticamente superiores ao grupo $3(\mathrm{p}<0,05)$.

$\mathrm{Na}$ avaliação do Índice de Remanescente do adesivo (IRA), os escores foram observados dentro de cada grupo, como mostrado na tabela 2.

Entre os grupos 1 e 2 ( $\mathrm{p}=0$,4059), não foram encontradas diferenças estatísticas significantes na avaliação do IRA. Entretanto, diferenças estatísticas significantes foram observadas entre os grupos 1 e $3(p=0,0011)$ e 2 e $3(p=0,0151)$.

\section{DISCUSSÃO}

$\mathrm{Na}$ tentativa de facilitar os procedimentos durante a colagem ortodôntica, os fabricantes têm desenvolvido uma gama de materiais prometendo eficiência com diminuição de passos clínicos, facilitando o trabalho do ortodontista2,3,6,10,12,15,17.

Entre os materiais desenvolvidos com esse propósito cita-se os adesivos auto-condicionantes e os compósitos de pasta única. Entre os compósitos, destaca-se o Right-On, que por ser auto-polimerizável e não necessitar mistura torna o procedimento de colagem mais rápido ${ }^{8}$.

$\mathrm{Na}$ comparação de valores de resistência ao cisalhamento deste trabalho não foram encontradas diferenças estatísticas significantes entre o grupo 1 (Transbond XT convencional - controle) e o grupo 2 (Right-On seguindo as recomendações do fabricante). A semelhança entre os valores destes grupos (Grupo $1=7$,89; grupo $2=8,05$ ) demonstra que o Right-On é compatível com o Transbond XT para a colagem de acessórios ortodônticos ao esmalte. Essa boa resistência quanto da utilização do Right-On foi
Tabela 1 - Valores de resistência ao cisalhamento e análise estatística entre os grupos.

\begin{tabular}{ccc}
\hline grupos & média (MPa) & estatística \\
\hline 1 & $7,89(2,65)$ & $\mathrm{a}$ \\
2 & $8,05(2,10)$ & $\mathrm{a}$ \\
3 & $4,28(1,88)$ & $\mathrm{b}$ \\
\hline
\end{tabular}

Letras iguais - ausência de diferença estatística significante $(p>0,05)$.

Tabela 2 - Valores do Índice de Remanescente de Adesivo (IRA) para cada grupo.

\begin{tabular}{cccccc}
\hline \multicolumn{5}{c}{ escores do IRA } \\
grupos & $\mathbf{0}$ & $\mathbf{1}$ & $\mathbf{2}$ & $\mathbf{3}$ & posto médio \\
\hline $\mathbf{1}$ & 3 & 3 & 5 & 4 & 35,4000 \\
$\mathbf{2}$ & 4 & 5 & 3 & 3 & 30,1000 \\
$\mathbf{3}$ & 1 & 2 & 0 & 12 & 14,6000 \\
\hline
\end{tabular}

$0=$ nenhuma quantidade de adesivo aderido ao esmalte.

$1=$ menos da metade do adesivo aderido ao esmalte.

2 = mais da metade do adesivo aderido ao esmalte.

$3=$ todo 0 adesivo aderido ao esmalte.

também encontrada por Sunna e Rock ${ }^{18}$.

No grupo 3 foi utilizado o Right-On para a colagem de braquetes, porém com modificações na técnica sugerida pelo fabricante, apresentando baixos valores de adesão. Neste grupo o esmalte foi condicionado com Transbond Plus Self-Etching Primer e aplicação de agente de união na base do braquete. Os valores adesivos inferiores apresentados por este grupo reforçam que o compósito Right-On deve ser usado como preconizado pelo fabricante do produto.

Entre os grupos houve diferença estatística significante, o grupo 2 apresentou um resultado de resistência ao cisalhamento superior, se comparado ao grupo 3. Levando em consideração que as únicas diferenças entre os grupos foi em relação ao agente condicionante e de união, sugere-se que diferenças químicas entre os materiais testados geraram isso, contra-indicando o uso do Transbond Plus Self Etching Primer em superfície a ser colada com Right-On. Esses resultados corraboram com os de Willems, Carels e Verbeket ${ }^{19}$, que testaram o compósito Heliosi Orthodontics, e os de Bishara et al. ${ }^{2}$, que testaram os compósitos Clearfil Liner Bond 2 e 
J.C. Moritta Kuraway associado ao agente autocondicionante Transbond Plus Self Etching Primer.

A análise dos resultados do IRA revelou superioridade estatística do grupo 1. O grupo 3 foi condicionado com agente auto-condicionante Transbond Plus Self-Etching Primer apresentando valores inferiores do IRA, mostrando incompatibilidade química do ácido primer com o compósito Right-On.

\section{CONCLUSÕES}

1) O Transbond XT convencional e o Right-On obtiveram bons resultados de resistência ao cisa- lhamento, quando colados seguindo as orientações do fabricante.

2) No grupo onde foi feita modificação na técnica de colagem, o valor de resistência ao cisalhamento foi inferior.

3) Em todos os grupos, a maioria das fraturas ocorreu na interface braquete/compósito, restando material aderido ao esmalte após a descolagem.

\title{
Evaluation of the shear bond strength of the Right-On composite under different enamel conditions
}

\begin{abstract}
Objective: To evaluate the shear bond strength of metallic brackets bonded with Right-On composite under different enamel conditions. Materials and methods: Forty-five bovine permanent lower incisors were used, and were divided into three groups $(n=15)$. For group 1 (control), the bonding procedures were performed by using Transbond XT according to the manufacturer's recommendations, that is $37 \%$ phosphoric acid etching, washing, drying, application of primer XT and, finally, the bonding procedure itself. For the other two groups, the brackets were bonded by using the Right-On composite. The bonding procedures for group 2 were performed according to the manufacturer's recommendations, that is $37 \%$ phosphoric acid etching, application of the composite activation liquid, both on the etched surface and the bracket's base, and insertion of the composite on the bracket's base and bracket positioning. In group 3, the dental surface was etched by using Transbond Plus Self-Etching Primer, and the composite activator liquid was applied on the bracket's base only. Following the bonding procedures, the shear bond strength test was performed by using an Instron machine at the speed of $0.5 \mathrm{~mm} / \mathrm{min}$. for mechanical tests. Results and conclusion: Results showed no statistical differences between groups 1 and 2 ( $p>0.05)$. However, both groups were statistically superior to group $3(p<0.05)$. A greater number of fractures on the bracket/ composite interface was evidenced by the ARI results.
\end{abstract}

Key words: Shear strength. Dental bonding. Brackets.

\section{REFERÊNCIAS}

1. ARTUN, J.; BERGLAND, S. Clinical trials with crystal growth conditioning as an alternative to acid-etch enamel pretreatment. Am. J. Orthod., St. Louis, v. 85, no. 4, p. 333-340, Apr. 1984.

2. BISHARA, S. E. et al. Evaluation of a new light-cured orthodontic bonding adhesive. Am. J. Orthod. Dentofacial Orthop., St. Louis, v. 114, no. 1, p. 80-87, July 1998.

3. BISHARA, S. E. et al. Effect of an acidic primer on shear bond strength of orthodontic brackets. Am. J. Orthod. Dentofacial Orthop., St. Louis, v. 114, no. 3, p. 243-247. Sept. 1998.
4. BISHARA, S. E. et al. Effect of time on the shear bond strength of glass ionomer and composite orthodontic adhesives. Am. J. Orthod. Dentofacial Orthop., St. Louis, v. 116, no. 6, p. 616-620, Dec. 1999.

5. BOYD, R. L. Periodontal considerations in the use of bans or donds on molars in adolescents and adults. Angle Orthod., Appleton, v. 62, no. 3, p. 117-120, May 1982.

6. BUONOCORE, M. G. A. A simple method of increase the adhesion of acrylic filling materials to enamel surfaces. J. Dent. Res., Alexandria, v. 34, no. 6, p. 849-853, Dec. 1955. 
7. BuONOCORE, M. G. Retrospections on bonding. Dent. Clin. North Am., Philadelphia, v. 25, no. 2, p. 242-255, Apr. 1981.

8. DELPORT, A.; GROEBLER, S. R. A laboratory evaluation of the tensile bond of strength of some orthodontic bonding resins to enamel. Am. J. Orthod. Dentofacial Orthop., St. Louis, v. 93, no. 2, p. 133-137, Feb. 1988.

9. GORELIK, L. et al. Bonding metal brackets with a selfpolymerizing sealant composite: a 12 month assessment. Am. J. Orthod., St. Louis, v. 75, no. 5, p. 542-553, May 1977.

10. HOBSON, R. S.; LEDVINKA, J.; MEECHAN, J. G. The effect of moisture and blood contamination on bond strength of a new orthodontic bonding material. Am. J. Orthod. Dentofacial Orthop., St. Louis, v. 120, no. 1, p. 54-57, July 2001.

11. IANNI FILHO, D. et al. Avaliação in vitro da força de adesão de materiais de colagem em Ortodontia: ensaios mecânicos de cisalhamento. Rev. Dental Press Ortodon. Ortop. Facial, Maringá, v. 9, n. 1, p. 39-48, jan./fev. 2004.

12. LITTLEWOOD, S. J. et al. Investigation of a hydrophilic primer for orthodontic bonding: an in vitro study. J. Orthod. London, v. 27, no. 2, p. 181-186, May/Aug. 2000.

13. NORDENVALL, K. J.; BRANSTRON, M.; MALMGREN, T. The effect of various pretreatment methods of the enamel in bonding procedures. Am. J. Orthod., St. Louis, v. 74, no. 4, p. 522- 530, Apr. 1978

14. PASCOTO R. C. Avaliação das propriedades anticariogênicas do cimento de ionômero de vidro utilizado na fixação de bráquetes ortodônticos: estudo in vitro. 1999. Tese (Doutorado)-Faculdade de Odontologia de Bauru, Universidade de São Paulo, Bauru, 1999.
15. ROMANO, F. L.: RUELLAS, A. C. O. Estudo comparativo in vitro da resistência ao cisalhamento da colagem e do índice de remanescente resinoso entre os compósitos concise e superbond. Rev. Dental Press Ortodon. Ortop. Facial, Maringá, v. 8, n.1, p. 69-75, jan./fev. 2003.

16. SADLER, J. F. A survey of some commercial adhesives: their possible application in clinical Orthodontics. Am. J. Orthod. St. Louis, v. 44, no. 1, p. 65-69, Jan. 1958

17. SCHANEVELDT, S.; FOLEY, T. F. Bond strength comparison of moisture-insensitive primers. Am. J. Orthod. Dentofacial Orthop., St. Louis, v. 122, no. 3, p. 267-273, Sept. 2002.

18. SUNNA, S.; ROCK, W. P. An ex vivo investigation into the bond strength of orthodontic brackets and adhesive systems. Br. J. Orthod., Oxford, v. 26, no. 4, p. 47-50, 1999.

19. WILLEMS, G.; CARELS, C. E. L.; VERBEKET, G. In vitro peel/ shear bond strength of orthodontic adhesives. J. Dent., Bristol, v. 25, no. 3-4, p. 263-270. 1997.

20. ZACHRISSON, B. U. Bonding in Orthodontic. In: GRABER, T. M.; WAIN, B. F. Orthodontic current principle and technique. St. Louis: C. V. Mosby, 1985. p. 485-563.
Endereço para correspondência

Matheus Melo Pithon

Av. Otávio Santos 395, $7^{\circ}$ andar sala 705 - Centro Odontomédico

Dr. Altamirando da Costa Lima - Vitória da Conquista/BA

CEP: 45.020-750 - E-mail: matheuspithon@bol.com.br 